\title{
Study the Removal of Fluoride from Aqueous Medium by Using Nano-Composites
}

\author{
Tapan K. Rout ${ }^{1}$, Reeta Verma ${ }^{2}$, Robert V. Dennis ${ }^{3}$, Sarbajit Banerjee ${ }^{3}$ \\ ${ }^{1}$ Research \& Development, Tata Steel Ltd., Jamshedpur, India \\ ${ }^{2}$ Department of Environment, Birla Institute of Technology (BIT), Mesra, Ranchi, India \\ ${ }^{3}$ Department of Chemistry, Texas A\&M University, College Station, TX, USA \\ Email: tkrout5@yahoo.com
}

Received 3 February 2015; accepted 1 March 2015; published 6 March 2015

Copyright (C) 2015 by authors and Scientific Research Publishing Inc.

This work is licensed under the Creative Commons Attribution International License (CC BY).

http://creativecommons.org/licenses/by/4.0/

(c) () Open Access

\begin{abstract}
Endemic fluorosis disease has become a major geo-environmental health care issue caused by fluoride ion. High-efficiency and low-cost materials to uptake fluoride from water have been a challenge for scientists and engineers. Here, we report a low-cost process by utilising low-cost starting materials to develop nanocomposite adsorbents for fluoride uptake from water. Bermuda grass as a starting source material converted into nanocomposite carbon fibers upon heat treatment at $800^{\circ} \mathrm{C}$ for one hour in Nitrogen atmosphere in the presence of metal oxides. Iron oxide-based nanocomposite (IBNC) is performing high $(\approx 97 \%)$ removal of fluoride ion at a contact time of 60 minutes (pH 4) followed by titania-based nanocomposite (TBNC) ( $292 \%$ ) and micro carbon fiber $(\approx 88 \%)$ respectively. The phenomenon of fluoride ion uptake is realised by Freundlich adsorption model, and both adsorption capacity and adsorption intensity for IBNC are higher than those for TBNC and micro carbon fiber.
\end{abstract}

\section{Keywords}

Adsorption, Nano-Oxides, Grafted Carbon Fiber, Thermal CVD, Fluoride

\section{Introduction}

Over the years groundwater has been regarded as the safest and most protected source of water, fit for drinking without treatment. There is a modest consideration given to the risks of chemical pollution, particularly to the presence of elevated levels of fluoride, arsenic and nitrate in groundwater. Recent studies, however, show the alarming threat of groundwater contaminations and the urgent need to find a low-cost treatment process for hazardous elements prior to drinking in different regions of the world. Specifically in the case of fluoride ions, con-

How to cite this paper: Rout, T.K., Verma, R., Dennis, R.V. and Banerjee, S. (2015) Study the Removal of Fluoride from Aqueous Medium by Using Nano-Composites. Journal of Encapsulation and Adsorption Sciences, 5, 38-52. 
sumption of water having excess fluoride over a prolonged period leads to a chronic disease known as fluorosis [1]-[4]. Fluoride is normally present in the form of fluoride ions in minerals, found in sedimentary (limestone and sandstone) and igneous (granite) rocks, and leached out to contaminate water through geological processes. Higher fluoride levels in the groundwater get through these minerals by volcanic and fumarolic processes. Dissolution of these barely soluble minerals depends on the water composition and the time of contact between the source minerals and the water. Fluoride in drinking water may be beneficial or detrimental depending on its concentration [5]. The upper limit of fluoride concentration in the natural drinking water is $1.5 \mathrm{mg} / \mathrm{L}$ according to the guidelines for drinking water quality [6]-[8].

Natural water is becoming enriched with fluoride by the means of (a) geological processes, and (b) industry. Water contamination by industry stems from many areas including: effluent discharge, fertilizers \& pesticides, fluorosilicone and fluorocarbon polymer synthesis, coke manufacturing, glass and ceramic manufacturing, electronics manufacturing, electroplating operations, steel and aluminum manufacturing, metal etching (with hydrofluoric acid), and wood preservatives. Average fluoride values for aluminium reduction plants are reported as 107 - $145 \mathrm{mg} / \mathrm{L}$ in waste water streams [4]. Concentrations of an order of magnitude greater have been reported for glass manufacturing, ranging from 1000 to $3000 \mathrm{mg} / \mathrm{L}$ of fluoride [5] [6]. Fluoride wastes are also generated in the steel manufacturing industry from the sintering and steel-making processes [7]-[12]. In the sintering plant fluoride is found as an impurity of limestone, where both fluorspar $\left(\mathrm{CaF}_{2}\right)$ and limestone are among the basic materials used in steel making and as such, contributed as the principal source for this industry of fluoride containing wastewater.

Incidences of high fluoride groundwater have been reported from 23 nations around the globe [13]. Endemic fluorosis has become a major geo-environmental health issue in many developing countries of the world. The Bureau of Indian Standards outlined Indian standards stating that $1 \mathrm{mg} / \mathrm{L}$ was the maximum permissible limit of fluoride with further remarks stating "the lesser the better" [14]. Of the fluoride deposits of 85 million tons on the earth's crust, 12 million tons are found in India [15]. Seventeen states in India are endemic for fluorosis [16] [17]. About 25 million people in India suffer from fluorosis and another 66 million are at risk [18]. It was stated in 1993 that crippling skeletal fluorosis might occur in people who have ingested fluoride of 10 - $20 \mathrm{mg}$ per day over 10 to 20 years. Early stages of skeletal fluorosis start with pain in bones and joints, muscle weakness, stiffness of joints, and chronic fatigue. During later stages of fluorosis, calcification of the bones takes place; osteoporosis in long bones and symptoms of osteosclerosis appear where the bones become denser and develop abnormal crystalline structure [19]. General skeletal fluorosis directly affects the economy of villagers (mostly tribal populations) as it causes illness and debilitation not only in humans but also in their domestic animals, on which they depend for their basic income [20]. Asian countries mainly India and China are worst affected. In 1993, 5 million people in Mexico (about 6\% of the population) were affected by fluoride in groundwater [21]. Fluorosis is prevalent in some parts of central and western China, caused not only by drinking fluoride that is in the groundwater but also by breathing airborne fluoride released from the burning of fluoride-laden coal. Worldwide such instances of industrial fluorosis are on the rise. Argentina in Latin America and East and North Africa are also endemic. Dental fluorosis is also caused due to damage of tooth enamel by the fluoride ion. Tooth enamel is made up of hydroxyapatite (87\%) which is a crystalline calcium phosphate [22]; the hydroxide ion of this enamel is displaced by the most stable fluorideion to form fluoroapatite, a trigger of dental fluorosis. Humans are most prone to this during the first 7 years of life. Dental fluorosis has been characterized and reported when fluoride ion intake levels rise above $1.5 \mathrm{mg} / \mathrm{L}$ for an extended period of time.

Several different materials have been used for defluoridation such as activated carbon (AC), tricalcium phosphate, synthetic ion exchangers, lime activated alumina, and alum. There have also been many methods developed to remove excessive fluoride from water including adsorption, ion exchange, precipitation, electrolysis, donnan dialysis, and electro dialysis [23]-[43]. Among these methods, adsorption is still one of the most extensively used and cheapest methods for defluoridation of water [44]-[51]. However, in recent years, a considerable amount of attention from scientists has been devoted to the study of different types of low-cost materials for fluoride uptake such as: spent bleaching earth, wollastonite and chine clay, bentonite and activated bentonite, kaolinitic clay, agricultural by-products, fly ash, carbon slurry, biogas residual slurry, zeolite, bone char, and flax shive [52]-[56]. Literature research has shown that alumina supported on carbon nanotubes $\left(\mathrm{Al}_{2} \mathrm{O}_{3} / \mathrm{CNT}\right)$ has a saturation adsorption capacity of $39.4 \mathrm{mg} / \mathrm{g}$ fluoride uptake. It is also found that the adsorption capacity of $\mathrm{Al}_{2} \mathrm{O}_{3} / \mathrm{CNT}$ is 3.0 - 4.5 times that of $\gamma-\mathrm{Al}_{2} \mathrm{O}_{3}$ while almost equal to that of IRA- 410 polymeric resin at $25^{\circ} \mathrm{C}$. The adsorption isotherms of fluoride on $\mathrm{Al}_{2} \mathrm{O}_{3} / \mathrm{CNT}$ fit the Freundlich equation well with the optimal $\mathrm{pH}$ ranging 
from 5.0 to 9.0. Crystalline and hydrous iron (III)-zirconium (IV) hybrid oxide (IZHO) at the optimum pH range between 4.0 and 7.0 provides good efficiency of fluoride uptake [29] [57]. The kinetic data obtained for fluoride adsorption on IZHO at pH $6.8( \pm 0.1)$ and room temperature (303 $\pm 2 \mathrm{~K})$ described that both the pseudo-firstorder and the reversible first-order equations are equally well $\left(r^{2}=\sim 0.98-0.99\right)$, and better than the pseudosecond-order equation $\left(r^{2}=\sim 0.96\right.$ - 0.98) for higher concentrations $\left(12.5\right.$ and $\left.25.0 \mathrm{mg} / \mathrm{dm}^{3}\right)$ of fluoride uptake. The synthesis of a zirconia/multi-walled carbon nanotube $\left(\mathrm{ZrO}_{2} /\right.$ MWCNTs) hybrid is also a novel sorbent for water defluoridation. The $\mathrm{ZrO}_{2}$ /MWCNTs were significantly more effective in fluoride removal than all other sorbents tested before, including $\mathrm{ZrO}_{2}$ impregnated carbons. The kinetics of fluoride adsorption on the mixed oxide is driven by boundary layer diffusion [58]-[60].

Recently, many researchers have worked on cost-effective fluoride adsorbents such as zeolites, metal-polymer \& metal-metal oxide composites as well as biomass materials like fishbone charcoal, Cynodon dactylon, chitosan, acacia Arabica plant, and Tamarindus indica. Mostly, biosorption adsorbents have shown the fluoride removal to be no better than $88 \%$, though this is still better than a metal oxide system. It has been proven that biosorption has good affinity selectively for ion uptake from aqueous solutions [61]-[65].

The present work focuses on a hybrid system for fluoride uptake where a low-cost biosorbent, using Bermuda grass (i.e., Cynodon dactylon) that is specially processed, leads to a novel fibrous material that once obtained and impregnated with titania and iron oxide in-situ by thermal chemical vapour deposition (thermal-CVD) technique, is ready for fluoride uptake.

\section{Materials and Methods}

\subsection{Processing of Bermuda Grass}

Bermuda grass is a natural bio fiber that is abundantly available in India which was specially processed for our investigation. The cleaned dry grass was pulverized and the fibrous powdered material was washed well with doubly distilled water to remove the free acid, followed by thermal treatment using chemical vapour deposition (CVD) setup at a heating rate of $50^{\circ} \mathrm{C} / \mathrm{min}$ in the presence of flowing $\mathrm{N}_{2}(250 \mathrm{~mL} / \mathrm{min})$. The heating continued up to a final temperature of $600^{\circ} \mathrm{C}$, where it was held for 5 minutes, to obtain thermally activated carbon without using any catalysts. The resulting product was cooled to room temperature and sieved to the desired particle sizes, namely 200 - 325 mesh (74 to $44 \mu \mathrm{m})$. Finally, the product was stored in vacuum desiccators until required for further experiments.

\subsection{Conversion of Micro Carbon Fiber to Nano Carbon Fiber Using Nano-Oxides}

The next set of experiments was conducted using catalysts such as $\mathrm{TiO}_{2}$ and $\mathrm{Fe}_{2} \mathrm{O}_{3}$ nano powders. Titania was procured from Aldrich chemical supplier whereas nanoiron oxide is plentiful available in our mill as waste by product of hot rolling steel. These catalysts were mixed with pulverized raw grass powder in the ratio of 1:100 (catalyst to grass powder) and fed into the CVD set up at a heating rate of $50^{\circ} \mathrm{C} / \mathrm{min}$ in the presence of $\mathrm{N}_{2}$ flow $(250 \mathrm{~mL} / \mathrm{min})$. The dwell time of the mixed samples was $1 \mathrm{~h}$ each and the rate of cooling was the same as that of heating. We could ascertain the optimum temperature for obtaining $\mathrm{Fe}_{2} \mathrm{O}_{3}$ based carbon nanofiber and $\mathrm{TiO}_{2}$ based carbon nanofiber is $800^{\circ} \mathrm{C}$ from their respective phase diagrams for carbide formation.

\subsection{Fluoride Adsorption Study}

In the present study, the derived nanocomposites were utilized for the removal of fluoride from its aqueous solution. The sorption isotherm and kinetics experiments were performed by batch adsorption experiments and were carried out by mixing $0.5 \mathrm{~g}$ (obtained by the study of effect of adsorbent dose) of sorbent with $100 \mathrm{~mL}$ of water containing sodium fluoride at $10 \mathrm{mg} / \mathrm{L}$ as initial fluoride concentration. The mixture was agitated in a thermostatic shaker at a speed of $250 \mathrm{rpm}$ at room temperature. The defluoridation studies were conducted for the optimization of various experimental conditions like contact time, initial fluoride concentration, adsorbent dose, and fluoride uptake with fixed dosage by varying $\mathrm{pH}$. All of the experiments were carried out at $30^{\circ} \mathrm{C} \pm 5^{\circ} \mathrm{C}$ temperature. Fluoride ion concentration was measured with an automatic ion analyzer using the equipment model Metrohm-TitriC based on ion chromatography principle and the $\mathrm{pH}$ of the solution was also measured by Orion ion selective equipment. All other water quality parameters were analyzed by using standard methods [66]. The effects of different dosages of biosorbent on fluoride uptake were studied by keeping the initial fluoride 
concentration and volume of the solution steady at $10 \mathrm{mg} / \mathrm{L}$ and $100 \mathrm{~mL}$, respectively, at $\mathrm{pH} 4$.

The fluoride concentration is retained in the adsorbent phase, qe (mg/g), was calculated according to [45],

$$
q e=\frac{(\mathrm{Co}-\mathrm{Ce})}{w} \cdot V
$$

where $q e$ is the amount of fluoride adsorbed (mg/g), $C o$ and $C e$ are the original/initial and residual concentration at equilibrium $(\mathrm{mg} / \mathrm{L})$, respectively, of fluoride in solution, $w$ is the weight of bi-adsorbents and $V$ is the volume of solution.

\subsection{Theory of Isotherm Models}

The abilities of two widely used isotherms such as the theoretical Langmuir and empirical Freundlich isotherms, to model the adsorption equilibrium data were examined. These models allow for an explanation about the nature of adsorption from the shape of the curve. Langmuir adsorption isotherm [45] is perhaps the best known of all isotherms, which is often applied in solid/liquid systems to describe the saturated monolayer adsorption. The linear form of the equation is used to describe the adsorption capacity for a particular range of adsorbate concentration. It can be represented as:

$$
q e=\frac{1}{q m} C e+\frac{1}{K a q m}
$$

where $C e$ is the equilibrium concentration (mg/L), qe is the amount of ion adsorbed (mg/g), $q m$ is a constant for a complete monolayer $(\mathrm{mg} / \mathrm{g})$, and $\mathrm{Ka}$ is an adsorption equilibrium constant $(\mathrm{L} / \mathrm{mg})$. The constants $q m$ and $\mathrm{Ka}$ can be determined from a linearized form of Equation (2) by the slope of the linear plot of Ce/qe versus Ce.

The Freundlich adsorption isotherm [67] is based on adsorption on a heterogeneous surface and is the earliest known relationship describing the adsorption equilibrium. The linear form of this equation is given by:

$$
\log q e=\log K_{F}+\frac{1}{n} \log C e
$$

where qe is the amount of ion adsorbed (mg/g), Ce is the equilibrium concentration (mg/L), $K_{F}$ and 1/n are empirical constants indicating the adsorption capacity and adsorption intensity, respectively. The plot of $\log q e$ versus $\log C e$ of Equation (3) results in a straight line and from the slope and intercept of the plot, the values for $n$ and $K_{F}$ can be obtained.

\subsection{Instrumental Analysis}

The surface morphology and size distribution of the micro carbon fiber and nanocomposites were analyzed by means of scanning electron microscopy (SEM) and transmission electron microscopy (TEM). The crystallinity and structure of the nanocomposites and the as-prepared activated carbon from grass were analyzed by X-ray diffraction (XRD).

\section{Results \& Discussion}

\subsection{XRD, SEM, and TEM Analysis for Nanocomposites}

The X-ray diffraction patterns have demonstrated that there were no peaks to indicate a crystalline structure (Figure 1(a)) of thermally treated grass at $600^{\circ} \mathrm{C}$. The absence of diffraction peaks confirms this material consists of amorphous fibers. XRD patterns of iron oxide and titania induced fiber showed a number of diffraction peaks for each which confirma crystalline product. In the case of iron oxide, the XRD shows the presence of magnetite, iron nitride and iron carbide (Figure 1(b)); while for titania the XRD, shown in Figure 1(c), confirms the presence of the anatase, rutile and brookite structure of $\mathrm{TiO}_{2}$ in the fiber. The XRD data of the iron oxide and titania nanoparticle induced fiber provide evidence of considerable modification of the untreated fiber structure (Figures 1(a)-(c)). The morphology of the fluoride treated adsorbents are shown through SEM and TEM. SEM of the untreated fiber from grass, iron oxide, and titania nanoparticle induced fiber are shown in Figures 2(a)-(c), respectively. The untreated micro carbon fiber exhibit carbon aggregated irregular surfaces with a large number of macrospores and crevices of various sizes at the surface. Carbon particles look like a 


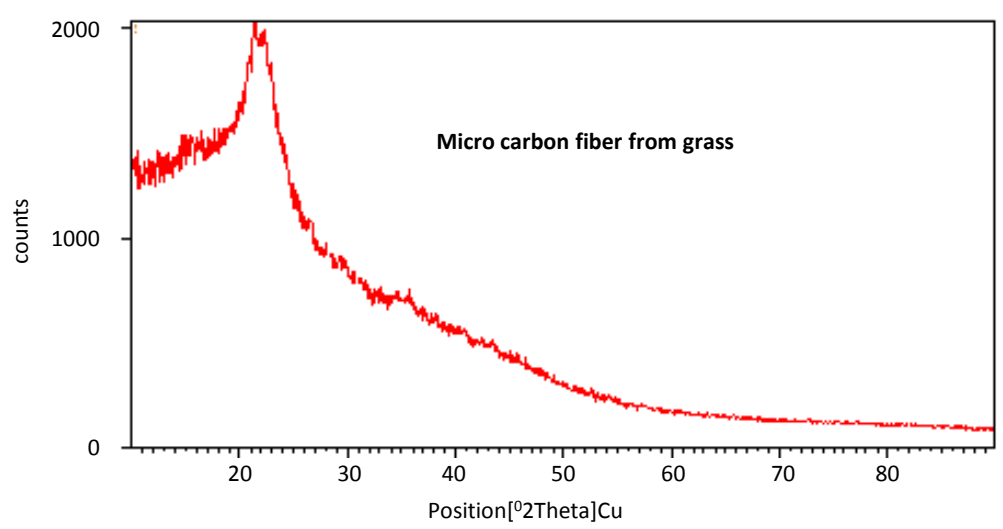

(a)

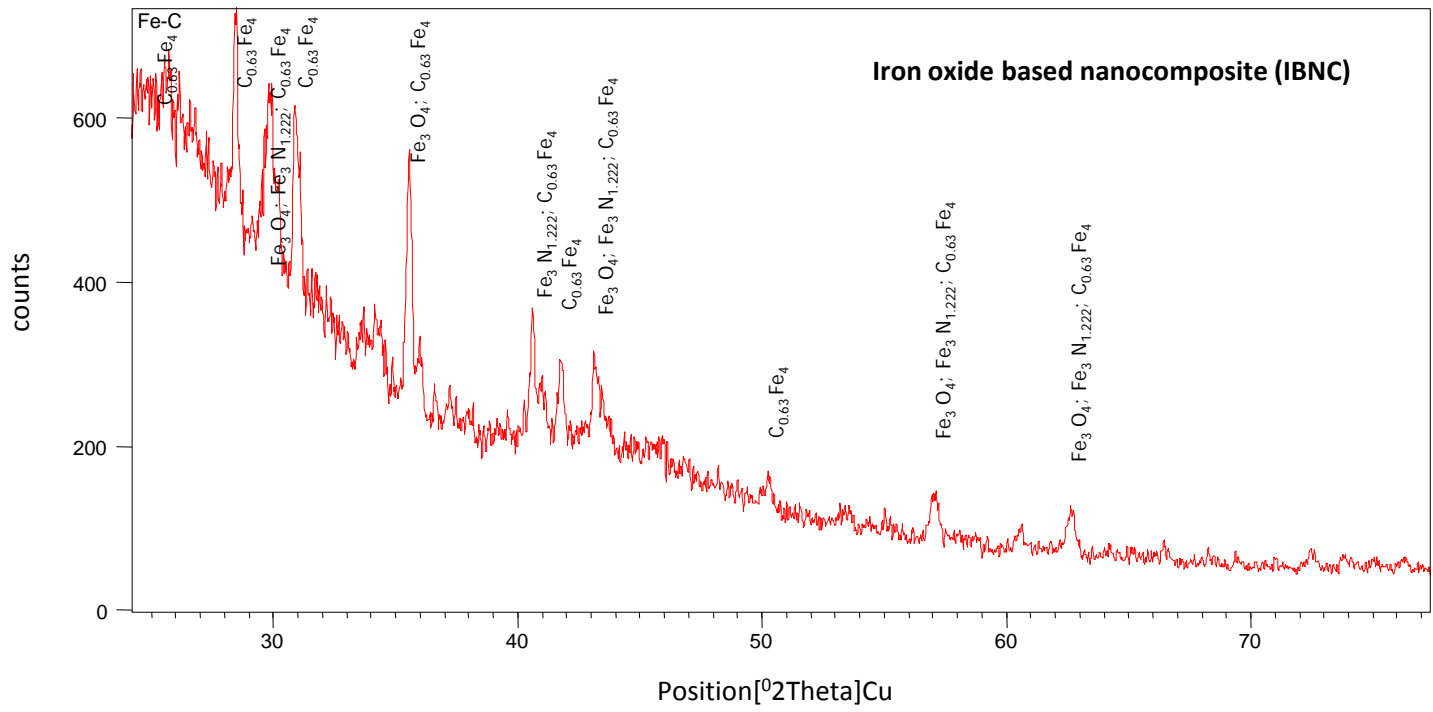

(b)

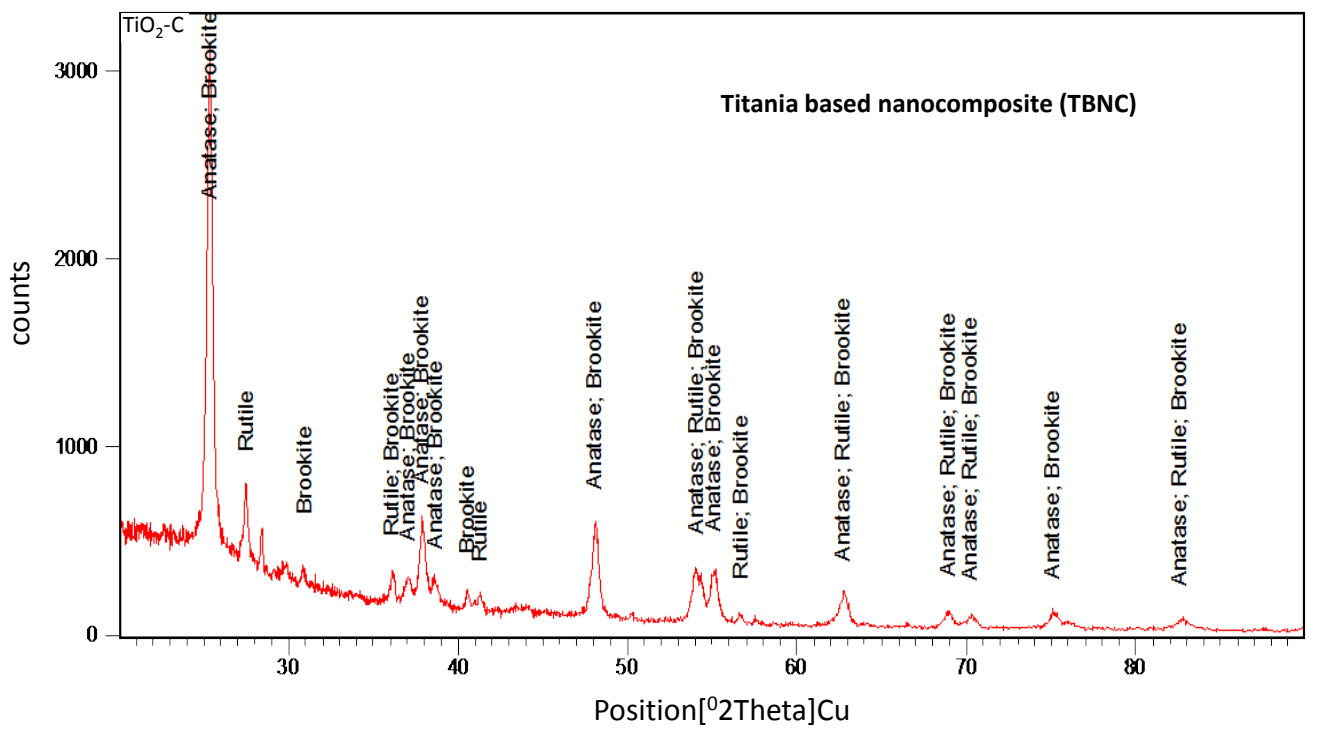

(c)

Figure 1. The XRD of the micro carbon from grass (a); The iron oxide based nanocomposite (b); The XRD of titania based nanocomposite (c). 


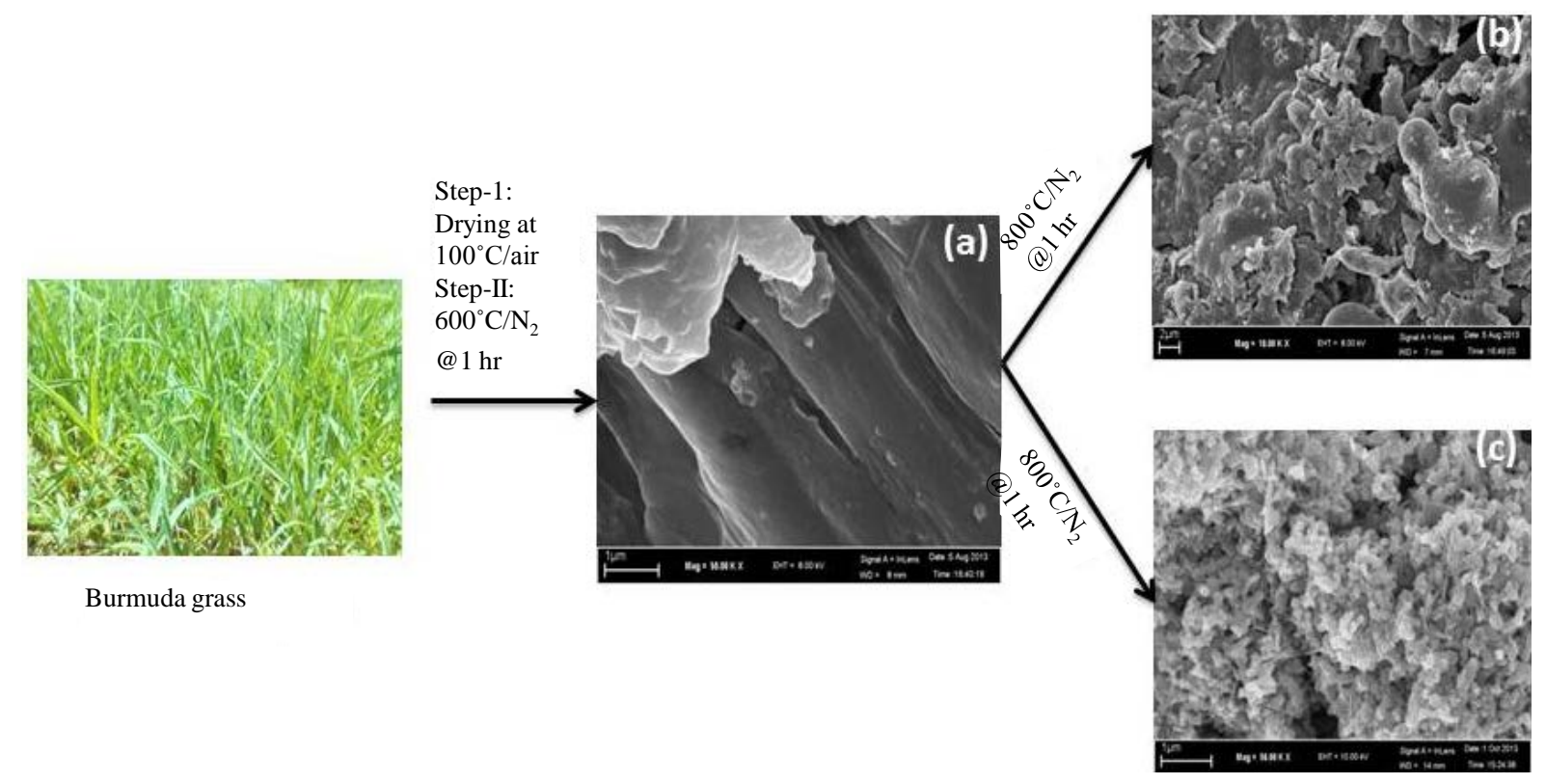

Figure 2. SEM images of (a) micro carbon fiber form grass, (b) IBNC, (c) TBNC.

maze of interconnecting channels, quite large at the surface and terminating in small channels in the interior [57]. This is indicative of carbon that is a good adsorbent base for the adsorption of pollutants from wastewaters. Figure 2(b) showed that the particles of iron oxide grafted to carbon giving rise to a highly irregular surface with large microspores and Figure 2(c) showed that the titania grafted carbon has irregular surfaces with various microstructures, including rods and spheres. TEM shown in Figure 3(a) and Figure 3(b) presents agglomeration of different particle sizes with spherical shapes showing both macro and micropores, and a few voids and crevices. In contrast, the TEM of titania grafted carbon, in Figure 3(c), showed a multi-modal distribution of particles size and solid titania rods are distributed irregularly [68]. Figure 3(c) also clearly reveals that the outer and inner diameter of the $\mathrm{TiO}_{2}$ rods is around $8-10$ and $5-7 \mathrm{~nm}$, respectively, and they have an open-end structure. From the above studies, we observed that these metal oxides have able to convert micro carbon fiber into nanocarbon fiber, and the same process oxides have been changed into nanoparticles of different shapes. Scanning electron microscopy (SEM) and TEM images of the iron nanocomposite showing small nanoparticles were distributed on the surface of the carbon fiber homogenously, decorated with nanoparticles of size 5 to 20 $\mathrm{nm}$ in diameter. The small size and uniformity of these nanoparticles was maintained after the $800^{\circ} \mathrm{C}$ treatment; apparently the strong interaction between the cabonfiber and the nanoparticles prevented their aggregation. This process is very simple and scalable in both the case. The embedded metal nanoparticles on the surface of cabon from TEM images are clearly affirming that a solid state thermal chemical reaction has been occurred between carbon fiber and metal oxides during the process. There was no much distance between the metal nanoparticles and the carbon surface which is indicating that the carbon has taken place in the chemical reaction. It is possible that the carbon fiber did chemically participate in the reaction by reducing the activation energy for the transformation of the metal oxides. This will require more detailed investigations in future studies. Nevertheless the proximity of metal nanoparticle to the carbon surface is expected to alter the surface charge of the carbon fibers, which can be probed via zeta potential study. Results of micro carbon fiber, IBNC and TBNC have been explained as under adsorption section. SEM of the fluoride treated IBNC surface is shown in Figure 3(d), which is different from the untreated fluoride surface and has confirmed that fluorides are adsorbed on the surface regardless of surface irregularities.

\subsection{Effect of Contact Time and Initial Fluoride Concentration}

Contact time plays a very important role in the adsorption dynamics. The effect of contact time on adsorption of fluoride onto fiber is shown in Figure 4. Batch adsorption studies using the concentrations 2.0, 3.0, 4.0, 6.0, 8.0 and $10.0 \mathrm{mg} / \mathrm{L}$ of fluoride solution and with $0.5 \mathrm{~g}$ of the adsorbent were carried out at $30^{\circ} \mathrm{C} \pm 5^{\circ} \mathrm{C}$ as a function 

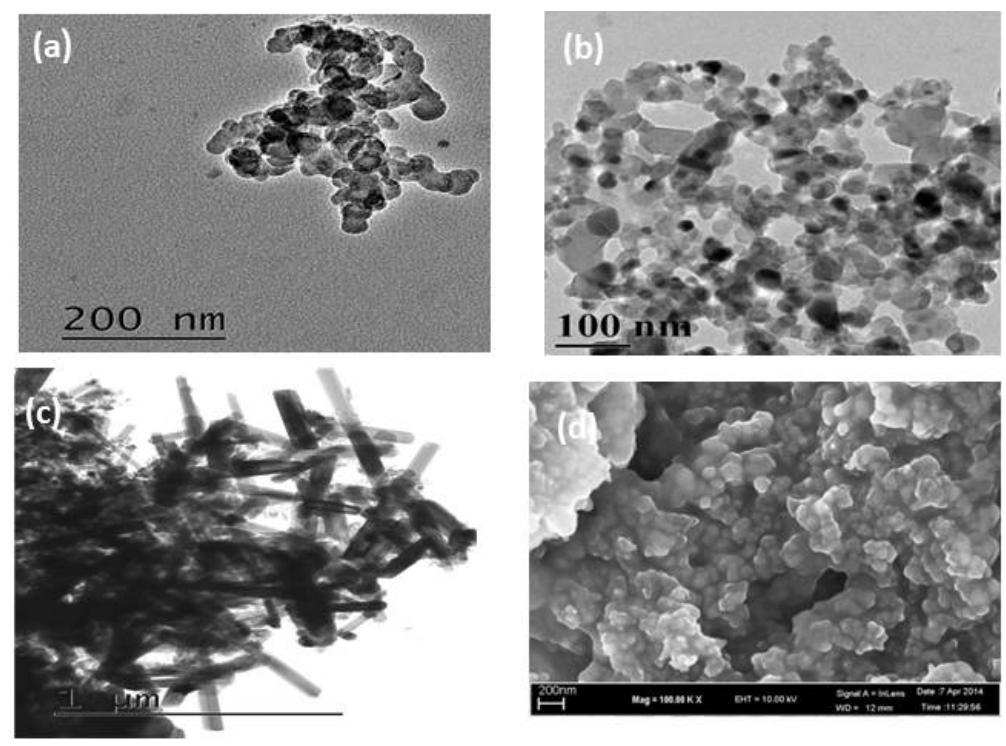

Figure 3. TEM photographs of (a) micro carbon fiber, (b) IBNC, (c) TBNC, (d) SEM image of IBNC surface after fluoride adsorption.

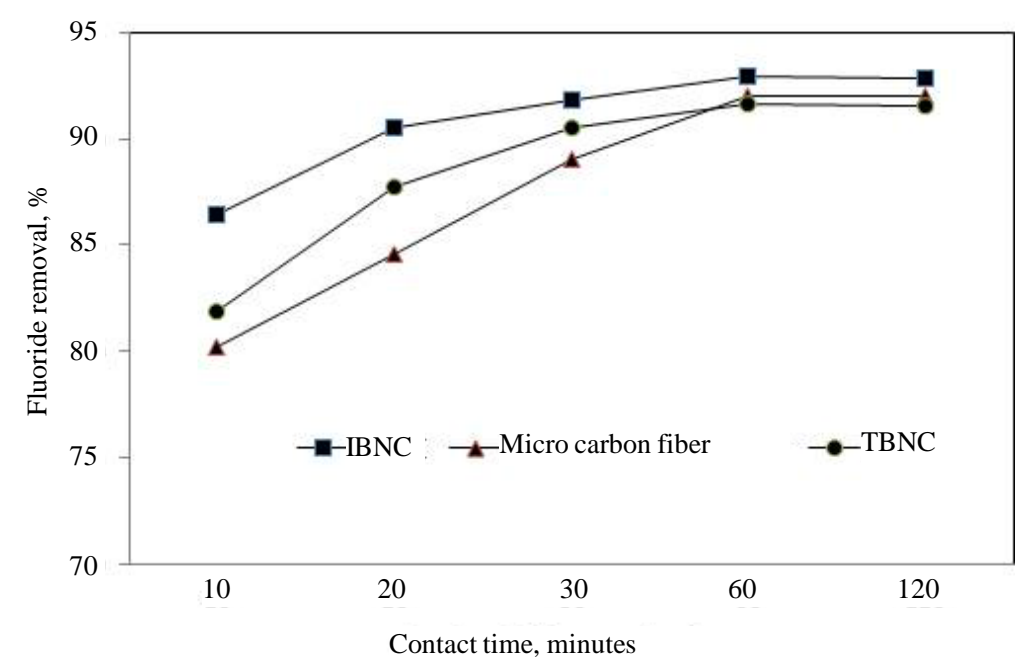

Figure 4. Effect of contact time on removal of fluoride on $0.5 \mathrm{~g}$ of adsorbents in water.

of time to evaluate the defluoridation and adsorption rate constants. The adsorption of fluoride increases with time and gradually attains equilibrium after 60 minutes as shown in Figure 4. Therefore 60 minutes was fixed as minimum contact time for the maximum defluoridation of the sorbent. The adsorption of fluoride decreased from $99.5 \%$ to $92 \%$ by increasing fluoride concentration from 2.0 to $10.0 \mathrm{mg} / \mathrm{L}$ as shown in Figure 5. Further, it was observed that the removal curves are continuously decreasing indicating the possibility of the formation of multilayers of fluoride ion at the pore volume and interface of the adsorbent.

\subsection{Effect of $\mathrm{pH}$ and Adsorbent Dose}

The effect of $\mathrm{pH}$ on removal of fluoride was examined (Figure 6). Test mixtures containing initial fluoride ion concentration of $10 \mathrm{mg} / \mathrm{L}$ and $0.5 \mathrm{~g} / 100 \mathrm{~mL}$ of adsorbents were adjusted to various $\mathrm{pH}$ values both in acidic and alkaline ranges, mixed for $60 \mathrm{~min}$ and analyzed for residual fluoride ion concentration by ion chromatography. Observations from Figure 6 were made at $\mathrm{pH}$ levels of 2, 4, 6, 8, and 10 and these experiments were conducted separately for all three adsorbents. The $\mathrm{pH}$ was maintained at the desired value within \pm 0.2 by adding $0.5 \mathrm{~N}$ 


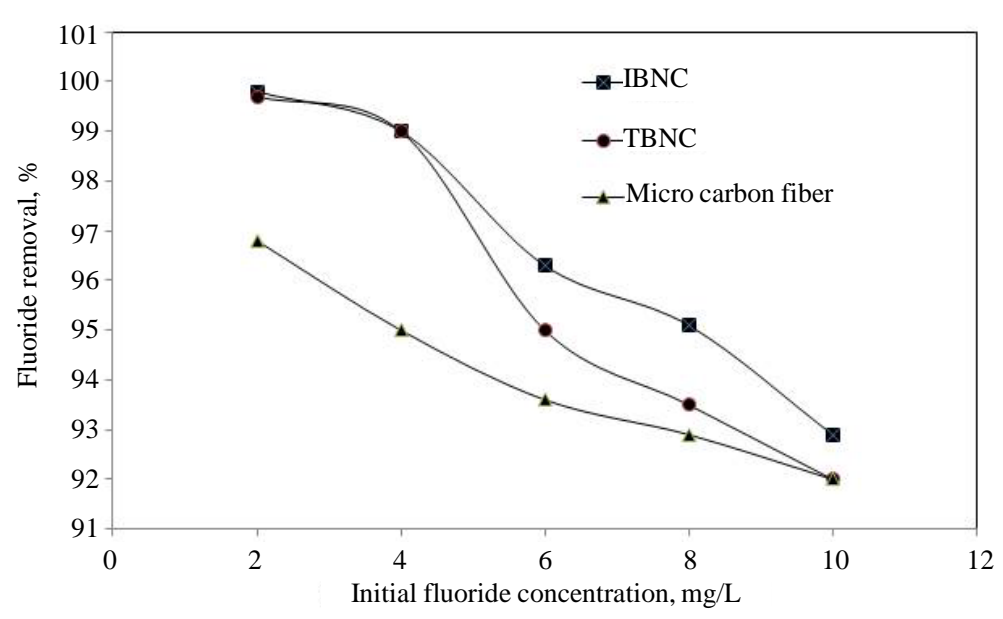

Figure 5. Effect of initial fluoride conc. on removal of fluoride on $0.5 \mathrm{~g}$ of adsorbents in water.

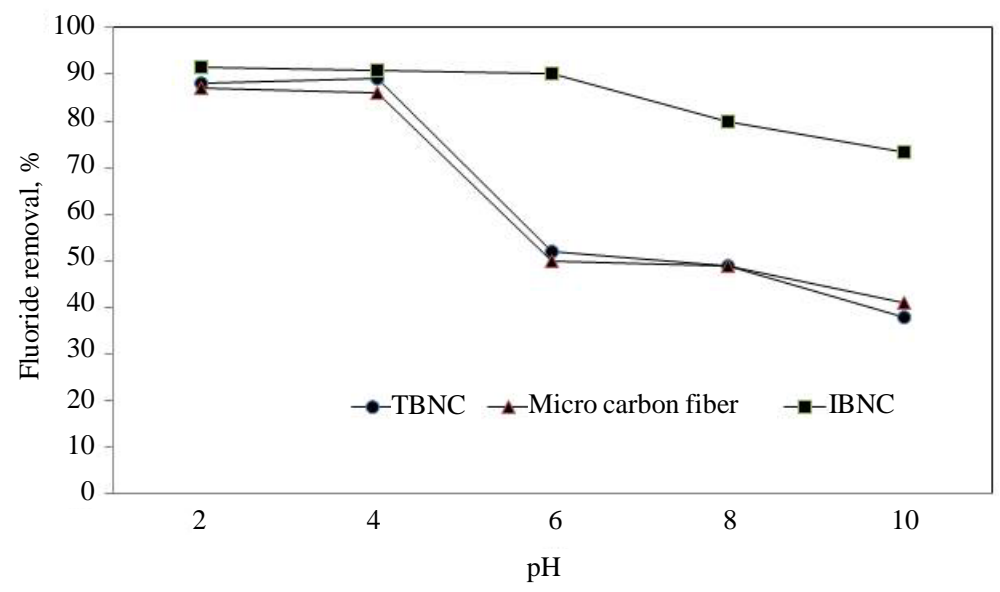

Figure 6. Effect of $\mathrm{pH}$ on removal of fluoride for $0.5 \mathrm{~g}$ of adsorbents in water.

$\mathrm{HNO}_{3}$ or $0.1 \mathrm{~N} \mathrm{NaOH}$. The percentage of fluoride ions removed decreases with increase in $\mathrm{pH}$ for all three adsorbents. At a pH of 2 to 4, which gives the maximum fluoride removal for both cases of metal oxide based fiber, about $97 \%$ and $92 \%$ of fluoride ions are removed for IBNC and TBNC, respectively (Figure 6).

The effect of adsorbent dosage on the removal of fluoride ions was examined by varying the adsorbent concentration from $0.1 \mathrm{~g} / 100 \mathrm{~mL}$ to $0.6 \mathrm{~g} / 100 \mathrm{~mL}$ while all other parameters were kept constant i.e., the initial fluoride ion concentration was $10 \mathrm{mg} / \mathrm{L}$ and the $\mathrm{pH}$ was 4 . The percentage of removed fluoride ion increases with an increase in adsorbent concentration for all three adsorbents, but after sometime, it gradually approaches a saturation value, denoting an equilibrium as shown in Figure 7. IBNC removes $87 \%$ of fluoride at a dose of 0.1 $\mathrm{g} / 100 \mathrm{mLand}$ increases to $97 \%$ removal at $0.5 \mathrm{~g} / 100 \mathrm{~mL}$ (Figure 7). The removal of fluoride ions increases from $84 \%$ to $92 \%$ when increasing the concentration of TBNC from $0.1 \mathrm{~g} / 100 \mathrm{~mL}$ to $0.5 \mathrm{~g} / 100 \mathrm{~mL}$ at a temperature of $35^{\circ} \mathrm{C} \pm 5^{\circ} \mathrm{C}$ (Figure 7).

\subsection{Adsorption Isotherms}

The equilibrium data isotherm analysis for fluoride adsorption onto the processed fiber from grass at $\mathrm{pH} 4.0 \pm$ 0.2 and $35^{\circ} \mathrm{C} \pm 5^{\circ} \mathrm{C}$ are shown in Figure 8. Results indicate that the adsorbent has a high affinity for fluoride ion adsorption under these conditions. As the concentration increases, adsorption capacity of fluoride also increases, but a plateau was gradually reached for all three materials when the concentration of fluoride is beyond $7 \mathrm{mg} / \mathrm{L}$. The equilibrium data has been analyzed by linear regression of isotherm model equations, Freundlich and Langmuir (Figure 9 and Figure 10, respectively). The related parameters were obtained by calculation from the 


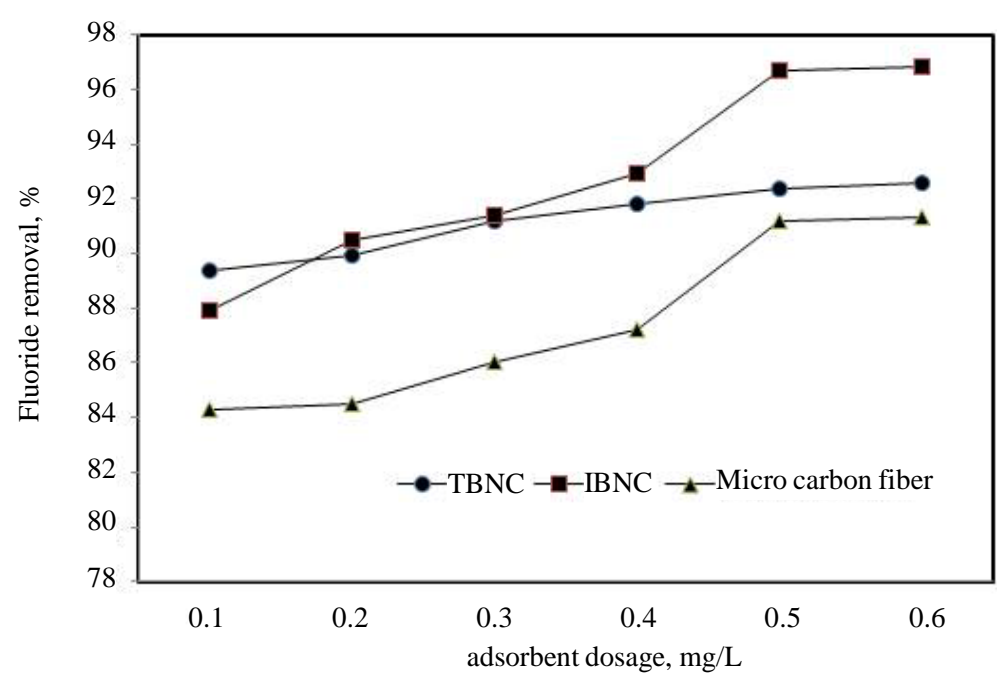

Figure 7. Effect of adsorbents dosage on removal of fluoride at Ph: 4 and contact time 60 min in water.

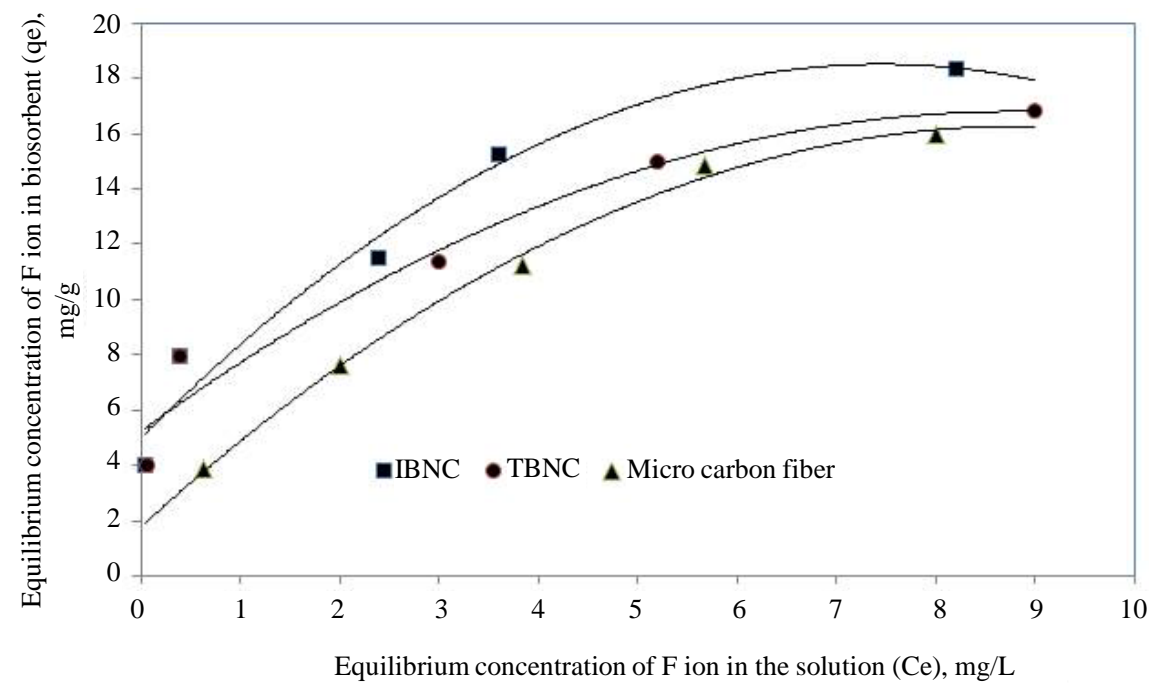

Figure 8. Effect of concentration on fluoride removal.

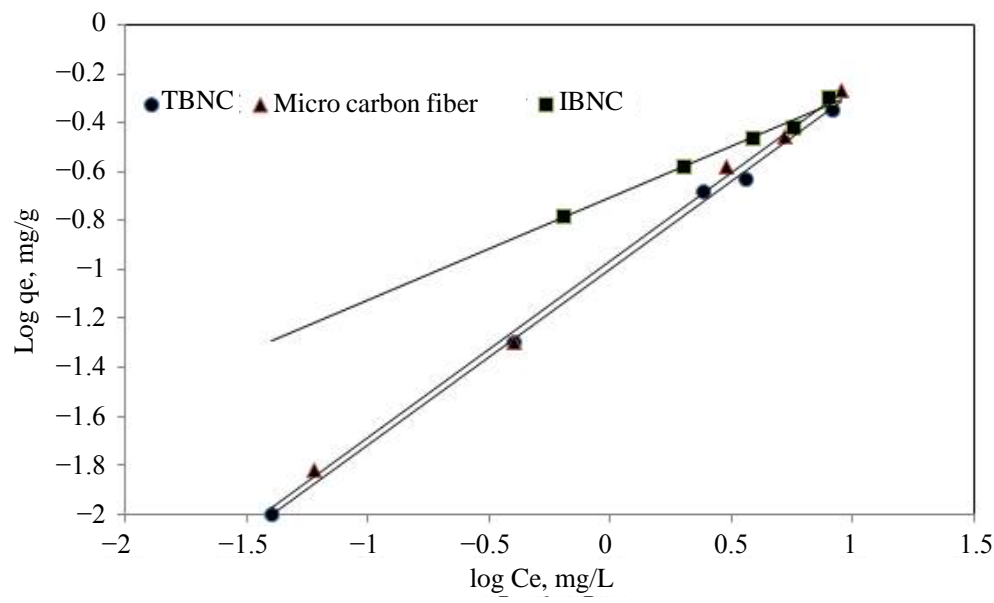

Figure 9. Effect of concentration on fluoride removal fits to Freundlich model. 


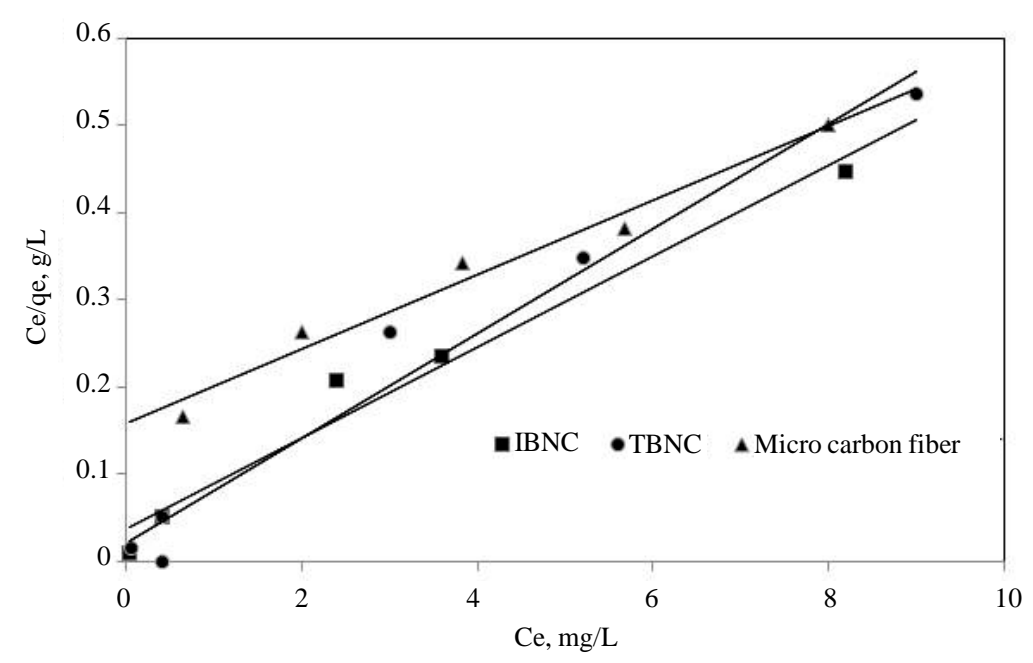

Figure 10. Effect of concentration on fluoride removal fits on Langmuir model.

values of the slopes and intercepts of the respective linear plots [69]. The present data fit the Freundlich models (Figure 9) well $\left(\mathrm{R}^{2}>0.99\right)$. The average adsorption capacity $\left(\log K_{F}\right)$ obtained for IBNC, TBNC, and fibrous carbon (from grass) is $0.41,0.72$, and 0.71 respectively, while the adsorption intensity $(n)$ is found to be 2.39 , 1.39, and 1.38, respectively. It is observed from the comparison of adsorption isotherms between IBNC, TBNC, as well as fiberous carbon (from grass) that both adsorption capacity and adsorption intensity for IBNC is found to be higher. With $n>1$, there is support for the favorable adsorption of fluoride onto these biosorbents. The linear plot for the Langmuir isotherm is shown in Figure 10. The relationship of linearity represented by Ce/qe versus $C e$ shows a correlation coefficient, $\mathrm{R}^{2}$, of 0.97 which is partially deviating from linearity. The present data is well fit to the Freundlich isotherm inferring multilayer adsorption is taking place on the surface of the biosorbent, due to ionic interactions. This finding is further explained by using adsorption potential theory [70] which explains that adsorptive forces originating from the well-known Van der Waals interaction can attract molecules at distances greater than a single molecular diameter. This force helps to reinforce the cohesive interaction between adsorbing molecules. Therefore, adsorbate molecules tend to concentrate at high energy sites on the modified fibrous carbon surface (nano carbon fiber) and undergo precipitation. The adsorption potential is highest in cracks and pores of the adsorbent, thus explaining the extensive adsorptive powers of fibrous carbon with its highly developed pore structure. Figure 11 represents a heterogeneous carbon surface and the broken lines represent the equipotential surface of having different energies (E), with the highest adsorbate concentration close to the surface, decreasing as one progresses away into the bulk of the solution. This is analogous to the atmospheric pressure gradient in a gravitational field. At $\mathrm{pH} 4$, zeta potential of the adsorbent surface for IBNC $(\xi=+4.07 \mathrm{mV})$, TBNC $(\xi=-0.72 \mathrm{mV})$, and micro fibrous carbon $(\xi=-5.56 \mathrm{mV})$ is found to be less negative as shown in Figure 12. Therefore, the electrostatic interaction of fluoride ion is different depending on the altered surface charge. IBNC has a high adsorption capacity and high adsorption intensity that may be due to dominating electrostatic interactions as well as Van der Wall forces existing between adsorbate and adsorbent.

IBNC cultivates a highly porous structure within each granule of carbon. The wall of these pores provides internal surface area. The surface area ranges from 500 to $1500 \mathrm{~m}^{2} / \mathrm{g}$ resulting in the extreme sorptive properties of these materials. Although adsorption is favorable in all cases, the adsorption capacity is following the sequence where IBNC $>$ TBNC > micro fiberous carbon, depending on the proximity to the surface. The more cracked and porous structure with positive surface potential has a high affinity to fluoride uptake as compared to others. The Freundlich model, which is an indicator of surface heterogeneity of the adsorbent, explains the observed phenomena with the experimental findings [71] [72].

\section{Conclusion}

The defluoridation studies of the biosorbent, i.e. processed Bermuda grass (Cynodon dactylon), have been carried out in batch mode. The most excellent defluoridation occurred at the optimum time of 60 minutes allowing for a success rate as high as $96 \%$ while keeping $10.0 \mathrm{mg} / \mathrm{L}$ fluoride concentration, $0.5 \mathrm{~g}$ dosage of adsorbent, 


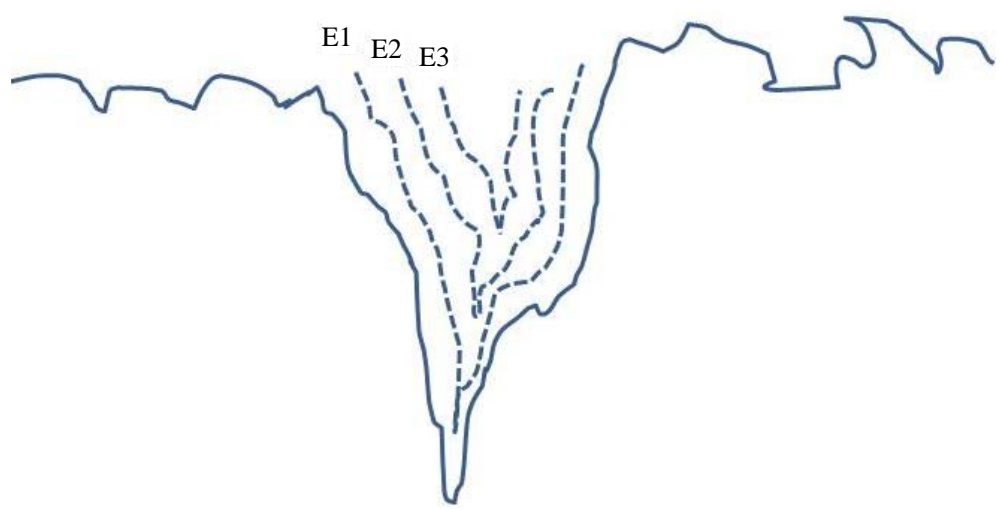

Figure 11. Representation of adsorption potential fields in activated carbon (Polanyi, M, 1916).

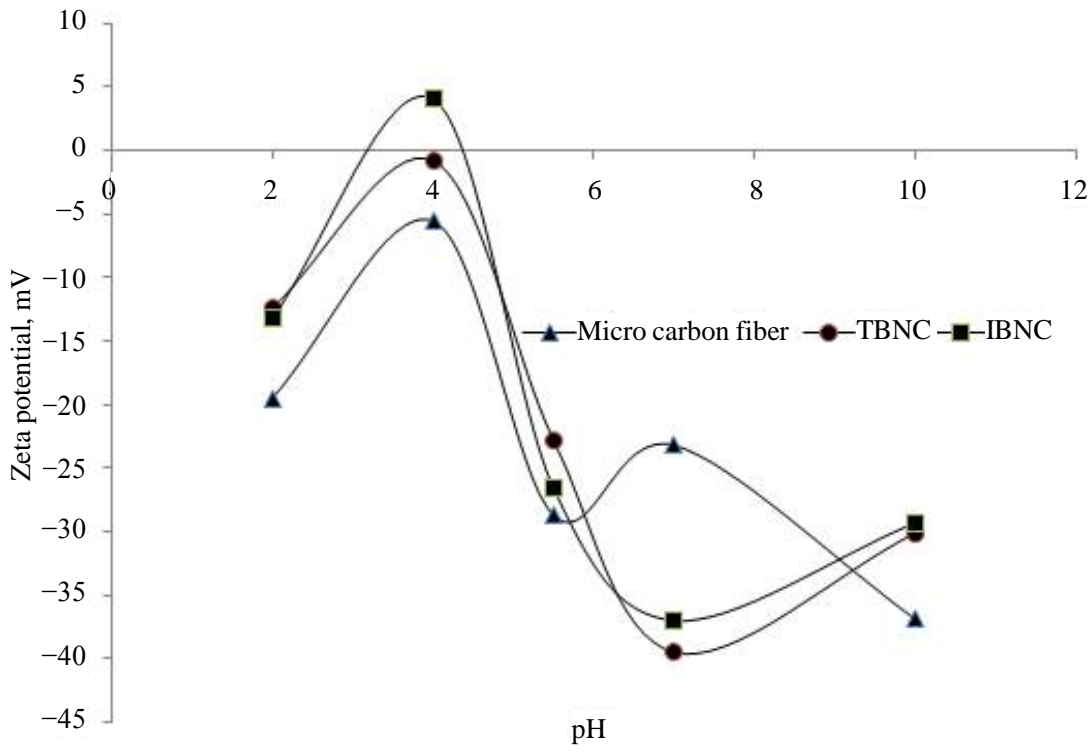

Figure 12. Effect $\mathrm{pH}$ on surface potential of adsorbents.

and $\mathrm{pH} 4$ constant. Thus, these materials show superior adsorptive efficiency as compared to previously studied defluoridation using natural adsorbents [8]-[10]. The presence of iron oxide particles is effective for the removal of fluoride using this adsorbent. The sorption of fluoride using this adsorbent followed the Freundlich model and the sorption process was found to be spontaneous in nature. Based on the above said description, iron oxide nanoparticle-induced biosorbent could be used to remove fluoride selectively from water.

\section{Acknowledgements}

The authors would like to thank the Tata Steel Management for providing support for this work and permission to publish. Special thanks to Mr. Anup Rout (Research Associate) for timely help for carrying out all experiments and data generation.

\section{References}

[1] Reddy, D.R. (2009) Neurology of Endemic Skeletal Fluorosis. Neurology India, 57, 7-12. http://dx.doi.org/10.4103/0028-3886.48793

[2] Jolly, S.S., Singh, I.D., Prasad, S., Sharma, R., Singh, B.M. and Mathur, O.C. (1969) An Epidemiological Study of Endemic Fluorosis in Punjab. Indian Journal of Medical Research, 57, 1333-1346.

[3] Saravanan, S., Kalyani, C., Vijayarani, M., Jayakodi, P., Felix, A., Nagarajan, S., Arunmozhi, P. and Krishnan, V. 
(2008) Prevalence of Dental Fluorosis among Primary Schoolchildren in Rural Areas of Chidambaram Taluk, Cuddalore District, Tamil Nadu. India. Indian Journal of Community Medicine, 33, 146-150. http://dx.doi.org/10.4103/0970-0218.42047

[4] Shortt, H.E., Pandit, C.G. and Raghvachari, T.N.S. (1937) Endemic Fluorosis in Nellore District of South India. Indian Medical Gazettiar, 72, 396-400.

[5] Susheela, A.K. (2001) Fluorosis: Indian Scienario: A Treatiseon Fluorosis. Fluorosis Research and Rural Development Foundation, New Delhi.

[6] WHO (2004) Guidelines for Drinking Water Quality. World Health Organization, Geneva.

[7] Venkobachar, C., Iyengar, L. and Mudgal, A. (1997) Household Defluoridation of Drinking Water Using Activated Alumina Technology. Dahi, E. and Nielsen, J.M., Eds., Proceedings of the 2nd International Workshop on Fluorosis and Defluoridation of Water, Addis Ababa, 19-22 November 1997, International Society for Fluoride Research, Dunedin.

[8] Andezhath, S.K. and Ghosh, G. (2000) Fluorosis Management in India: The Impact Due to Networking between Health and Rural Drinking Water Supply Agencies. IAHS AISH Publication, 260, 159-165.

[9] USEPA 440/1-74-024-a (1974) Development Document for Effluent Limitations Guidelines and New Source Performance Standards for the Steel Making Segment of the Iron and Steel Manufacturing Point Source Category.

[10] USEPA 440/1-75/040 (1975) Development Document for Interim Final Effluent Limitation Guidelines and Proposed New Source Performance Standards for the Common and Precious Metals Segment of the Electroplating Point Source Category.

[11] USEPA 440/1-75/034-a, Group l, Phasell (1975) Development Document for Effluent Limitations Guidelines and New Source Performance Standards for the Pressed and Blown Glass Segment of the Glass Manufacturing Point Source Category. Washington DC.

[12] UNICEF's Position on Water Fluoridation (2005) Fluoride in Water: An Overview. http://www.nofluoride.com/Unicef_fluor.cfm

[13] Agarwal, V., Vaish, A.K. and Vaish, P. (1997) Groundwater Quality: Focus on Fluoride and Fluorosis in Rajasthan. Current Science, 73, 743-746.

[14] Passmore, R., Nicol, B.M., Rao, M.N., Beaton, G.H. and Demayer, E.M. (1974) Handbook on Human Nutritional Requirements. World Health Organization Monograph Series, No. 61, Geneva, 1-66.

[15] Teotia, S.P. and Teotia, M. (1984) Endemic Fluorosis in India: A Challenging National Health Problem. Journal of the Association of Physicians of India, 32, 347-352.

[16] Rajiv Gandhi National Drinking Water Mission (1993) Prevention and Control of Fluorosis in India. Ministry of Rural Development, New Delhi.

[17] Kotecha, P.V., Patel, S.V., Bhalani, K.D., Shah, D., Shah, V.S. and Mehta, K.G. (2012) Prevalence of Dental Fluorosis \& Dental Caries in Association with High Levels of Drinking Water Fluoride Content in a District of Gujarat, India. Development Foundation, New Delhi. Indian Journal of Medical Research, 135, 873-877.

[18] Yadav, S., Khan, T.I., Gupta, S., Gupta, A.B. and Yadava, R.N. (1999) Fluorosis in India with Special Reference to Rajasthan. In: Proceedings of the International Conference on Water, Environment, Ecology, Socioeconomics and Health Engineering (WEESHE), Seoul National University, Seoul, 3-10.

[19] Monroy, S.D. (2011) Fluoride Properties, Applications and Environmental Management, 111-136.

[20] Chauhan, D., Chauhan, T., Sachdev, V. and Kirtaniya, B.C. (2012) A Study of Prevalence and Severity of Dental Fluorosis among School Children in a Northern Hilly State of India. SRM Journal of Research in Dental Sciences, 3, 170-174. http://dx.doi.org/10.4103/0976-433X.107395

[21] Grimaldo, M., Turrubiartes, F., Milan, J., Pozos, A., Alfaro, C. and Diaz-Barriga, F. (1997) Endemic Fluorosis in San Luis Potosi, Mexico. Fluoride, 30, 33-40.

[22] Brudevold, F. and Soremark, R. (1967) Structural and Chemical Organization of Teeth, Vol. 2. Miles, A.G.W., Ed., Academic Press, New York and London, 247.

[23] Bansiwal, A., Pillewan, P., Biniwale, R.B. and Rayalu, S.S. (2010) Copper Oxide Incorporated Mesoporous Alumina for Defluoridation of Drinking Water. Microporous and Mesoporous Materials, 129, 54-61. http://dx.doi.org/10.1016/j.micromeso.2009.08.032

[24] Bhaumika, M., Leswifia, T.Y., Maity, A., Srinivasu, V.V. and Onyango, M.S. (2011) Removal of Fluoride from Aqueous Solution by Polypyrrole/ $\mathrm{Fe}_{3} \mathrm{O}_{4}$ Magnetic Nanocomposite. Journal of Hazardous Materials, 186, 150-159. http://dx.doi.org/10.1016/j.jhazmat.2010.10.098

[25] Bia, G., Pauli, C.P.D. and Borgnino, L. (2012) The Role of Fe(III) Modified Montmorillonite on Fluoride Mobility: 
Adsorption Experiments and Competition with Phosphate. Journal of Environmental Management, 100, 1-9. http://dx.doi.org/10.1016/j.jenvman.2012.01.019

[26] Chen, N., Zhang, Z., Feng, C., Li, M., Zhu, D. and Sugiura, N. (2011) Studies on Fluoride Adsorption of Iron-Impregnated Granular Ceramics from Aqueous Solution. Materials Chemistry and Physics, 125, 293-298. http://dx.doi.org/10.1016/j.matchemphys.2010.09.037

[27] Das, N., Pattanaik, P. and Das, R. (2005) Defluoridation of Drinking Water Using Activated Titanium Rich Bauxite. Journal of Colloid and Interface Science, 292, 1-10. http://dx.doi.org/10.1016/j.jcis.2005.06.045

[28] Li, Y.H., Wang, S., Cao, A., Zhao, D., Zhang, X., Xu, C., Luan, Z., Ruan, D., Liang, J., Wu, D. and Wei, B. (2001) Adsorption of Fluoride from Water by Amorphous Alumina Supported on Carbon Nanotubes. Chemical Physics Letters, 350, 412-416. http://dx.doi.org/10.1016/S0009-2614(01)01351-3

[29] Yan, X.R., Song, K.X., Wang, J.P., Hu, L.C. and Yang, Z.H. (1998) Preparation of $\mathrm{CeO}_{2}-\mathrm{TiO}_{2} / \mathrm{SiO}_{2}$ and Its Removal Properties for Fluoride Ions. Journal of Rare Earths, 16, 279-280.

[30] Cui, H., Qian, Y., An, H., Sun, C., Zhai, J. and Li, Q. (2012) Electrochemical Removal of Fluoride from Water by PAOA Modified Carbon Felt Electrodes in a Continuous Flow Reactor. Water Research, 46, 3943-3950. http://dx.doi.org/10.1016/j.watres.2012.04.039

[31] Puri, B.K. and Balani, S. (2000) Trace Determination of Fluoride Using Lanthanum Hydroxide Supported on Alumina. Journal of Environmental Science and Health, Part A, 35, 109-121. http://dx.doi.org/10.1080/10934520009376957

[32] Ansari, M., Kazemipour, M., Dehghani, M. and Kazemipour, M. (2011) The Defluoridation of Drinking Water Using Multi-Walled Carbon Nanotubes. Journal of Fluorine Chemistry, 132, 516-520. http://dx.doi.org/10.1016/j.jfluchem.2011.05.008

[33] Swain, S.K., Patnaik, T., Singh, V.K., Jha, U., Patel, R.K. and Dey, R.K. (2011) Kinetics, Equilibrium and Thermodynamic Aspects of Removal of Fluoride from Drinking Water Using Meso-Structured Zirconium Phosphate. Chemical Engineering Journal, 171, 1218-1226. http://dx.doi.org/10.1016/j.cej.2011.05.030

[34] Cherry, J.M. (1970) Fluoride Recovery in Phosphate Manufacture. Water and Waste Engineering, 7, D5.

[35] Mohapatra, M., Hariprasad, D., Mohapatra, L., Anand, S. and Mishra, B.K. (2012) Mg-Doped Nano Ferrihydrite-A New Adsorbent for Fluoride Removal from Aqueous Solutions. Applied Surface Science, 258, 4228-4236. http://dx.doi.org/10.1016/j.apsusc.2011.12.047

[36] Guo, Q. and Reardon, E.J. (2012) Fluoride Removal from Water by Meixnerite and Its Calcination Product. Applied Clay Science, 56, 7-15. http://dx.doi.org/10.1016/j.clay.2011.11.013

[37] Ma, W., Ya, F., Wang, R. and Zhao, Y.Q. (2008) Fluoride Removal from Drinking Water by Adsorption Using Bone Char as a Biosorbent. International Journal of Environmental Technology and Management, 9, 59-69. http://dx.doi.org/10.1504/IJETM.2008.017860

[38] Dey, S., Swarup, D., Saxena, A. and Dan, A. (2011) In Vivo Efficacy of Tamarind (Tamarinds indica) Fruit Extract on Experimental Fluoride Exposure in Rats. Research in Veterinary Science, 91, 422-425. http://dx.doi.org/10.1016/j.rvsc.2010.09.013

[39] Mandal, S. and Mayadevi, S. (2009) Defluoridation of Water Using as-Synthesized Zn/Al/Cl Anionic Clay Adsorbent: Equilibrium and Regeneration Studies. Journal of Hazardous Materials, 167, 873-878.

[40] Kumar, N.P., Kumar, N.S. and Krishnaiah, A. (2011) Defluoridation of Water Using Tamarind (Tamarindus indica) Fruit Cover: Kinetics and Equilibrium Studies. Journal of the Chilean Chemical Society, 57, 1224-1231.

[41] Mohan, X.D.D., Pittman Jr., C.U. and Yang, S. (2012) Remediating Fluoride from Water Using Hydrous Zirconium Oxide. Chemical Engineering Journal, 198-199, 236-245. http://dx.doi.org/10.1016/j.cej.2012.05.084

[42] Poursaberi, T., Hassanisadi, M., Torkestani, K. and Zare, M. (2012) Development of Zirconium (IV)-Metalloporphyrin Grafted $\mathrm{Fe}_{3} \mathrm{O}_{4}$ Nanoparticles for Efficient Fluoride Removal. Chemical Engineering Journal, 189-190, 117-125. http://dx.doi.org/10.1016/j.cej.2012.02.039

[43] Ramanjaneyulu, V., Jaipal, M., Yasovardhan, N. and Sharada, S. (2013) Kinetic Studies on Removal of Fluoride from Drinking Water by Using Tamarind Shell and Pipal Leaf Powder. International Journal of Emerging Trends in Engineering and Development, 5, 146.

[44] Tripathy, S.S., Bersillon, J.L. and Gopal, K. (2006) Removal of Fluoride from Drinking Water by Adsorption onto Alum-Impregnated Activated Alumina. Separation and Purification Technology, 50, 310-317. http://dx.doi.org/10.1016/j.seppur.2005.11.036

[45] Langmuir, I. (1916) The Constitution and Fundamental Properties of Solids and Liquids. Part I. Solids. Journal of the American Chemical Society, 38, 2221-2295. http://dx.doi.org/10.1021/ja02268a002

[46] Sivasamy, A., Singh, K.P., Mohan, D. and Maruthamuthu, M. (2001) Studies on Defluoridation of Water by CoalBased Sorbents. Journal of Chemical Technology and Biotechnology, 76, 717-722. 
http://dx.doi.org/10.1002/jctb.440

[47] Sivasankar, V., Murugesh, S., Rajkumar, S. and Darchen, A. (2013) Cerium Dispersed in Carbon (CeDC) and Its Adsorption Behavior: A First Example of Tailored Adsorbent for Fluoride Removal from Drinking Water. Chemical Engineering Journal, 214, 45-54. http://dx.doi.org/10.1016/j.cej.2012.10.023

[48] Subramanian, E. and Ramalakshmi, R.D. (2010) Pristine, Purified and Polyaniline-Coated Tamarind Seed (Tamarindus indica) Biomaterial Powders for Defluoridation: Synergism and Enhancement in Fluoride Adsorption by Polyaniline Coating. Journal of Scientific and Industrial Research, 69, 621-628.

[49] Turner, B.D., Binning, P. and Stipp, S.L.S. (2005) Fluoride Removal by Calcite: Evidence for Fluorite Precipitation and Surface Adsorption. Environmental Science \& Technology, 39, 9561-9568. http://dx.doi.org/10.1021/es0505090

[50] Wajima, T., Umeta, Y., Narita, S. and Sugawara, K. (2009) Adsorption Behavior of Fluoride Ions Using a Titanium Hydroxide-Derived Adsorbent. Desalination, 249, 323-330. http://dx.doi.org/10.1016/j.desal.2009.06.038

[51] Camacho, L.M., Torres, A., Saha, D. and Deng, S. (2010) Adsorption Equilibrium and Kinetics of Fluoride on Sol-GelDerived Activated Alumina Adsorbents. Journal of Colloid and Interface Science, 349, 307-313. http://dx.doi.org/10.1016/j.jcis.2010.05.066

[52] Vithanagea, M., Jayarathnaa, L., Rajapakshaa, A.U., Dissanayakea, C.B., Bootharajub, M.S. and Pradeep, T. (2012) Modeling Sorption of Fluoride on to Iron Rich Laterite. Colloids and Surfaces A: Physicochemical and Engineering Aspects, 398, 69-75. http://dx.doi.org/10.1016/j.colsurfa.2012.02.011

[53] Sakhare, N., Lunge, S., Rayalu, R., Bakardjiva, S., Subrt, J., Devotta, S. and Labhsetwar, N. (2012) Defluoridation of Water Using Calcium Aluminate Material. Chemical Engineering Journal, 203, 406-414. http://dx.doi.org/10.1016/j.cej.2012.07.065

[54] Chakrabarty, S. and Sarma, H.P. (2012) Defluoridation of Contaminated Drinking Water Using Neem Charcoal Adsorbent: Kinetics and Equilibrium Studies. International Journal of ChemTech Research, 4, 511-516.

[55] Sylvester, R.O., Oglesby, R.T., Carlson, D.A. and Christman, R.F. (1967) Factors Involved in the Location and Operation of an Aluminium Reduction Plant. Proceedings of the 22nd Industrial Waste Conference, Purdue, 2-4 May 1967, 441-454.

[56] Romanos, J., Beckner, M., Rash, T., Firlej, L., Kuchta, B., Yu, P., et al. (2012) Nanospace Engineering of KOH Activated Carbon. Nanotechnology, 23, Article ID: 015401. http://dx.doi.org/10.1088/0957-4484/23/1/015401

[57] Wang, S.G., Li, Y.H., Zhao, D., Xu, C.L., Luan, Z.K., Liang, J. and Wu, D.H. (2002) Preparation of Alumina Supported on Carbon Nanotubes and Its Application in Fluoride Adsorption from an Aqueous Solution. Chinese Science Bulletin, 47, 722-724. http://dx.doi.org/10.1360/02tb9162

[58] Sarkar, M., Banerjee, A. and Pramanick, P.P. (2006) Kinetics and Mechanism of Fluoride Removal Using Laterite. Industrial \& Engineering Chemistry Research, 45, 5920-5927.

[59] Sivasankar, V., Rajkumar, S., Murugesh, S. and Darchen, A. (2012) Influence of Shaking or Stirring Dynamic Methods in the Defluoridation Behaviour of Activated Tamarind Fruit Shell Carbon. Chemical Engineering Journal, 197, 162172. http://dx.doi.org/10.1016/j.cej.2012.05.023

[60] Maliyekkal, S.M., Sharma, A.K. and Philip, L. (2006) Manganese-Oxide-Coated Alumina: A Promising Sorbent for Defluoridation of Water. Water Research, 40, 3497-3506. http://dx.doi.org/10.1016/j.watres.2006.08.007

[61] Gupta, A.K., Deva, D., Sharma, A. and Verma, N. (2009) Adsorptive Removal of Fluoride by Micro-Nanohierarchal Web of Activated Carbon Fibers. Industrial \& Engineering Chemistry Research, 48, 9697-9707. http://dx.doi.org/10.1021/ie801688k

[62] Sundaram, C.S., Viswanathan, N. and Meenakshi, S. (2009) Defluoridation of Water Using Magnesia/Chitosan Composite. Journal of Hazardous Materials, 163, 618-624. http://dx.doi.org/10.1016/j.jhazmat.2008.07.009

[63] Kishore, M. and Hanumantharao, Y. (2010) Validation of Defluoridation Method with “Acacia Arabica” Plant by Product through $2^{\mathrm{n}}$ Factorial Experimentation-A Statistical Approach. International Journal of Applied Biology and Pharmaceutical Technology, 1, 1230-1235.

[64] Martin, R.J. and Ng, W.J. (1997) The Repeated Exhaustion and Chemical Regeneration of Activated Carbon. Water Research, 21, 961-965. http://dx.doi.org/10.1016/S0043-1354(87)80014-3

[65] Mondal, N.K., Bhaumik, R., Baur, T., Das, B., Roy, P. and Datta, J.K. (2012) Studies on Defluoridation of Water by Tea Ash: An Unconventional Biosorbent. Department of Environmental Science, The University of Burdwan, Burdwan, Chemical Science Transactions, 1, 239-256.

[66] American Public Health Association (2007) Standard Methods for the Examination of Water and Waste Water. 14th Edition, Washington.

[67] Ayoob, S. and Gupta, A.K. (2008) Insights into Isotherm Making in the Sorptive Removal of Fluoride from Drinking Water. Journal of Hazardous Materials, 152, 976-985. http://dx.doi.org/10.1016/j.jhazmat.2007.07.072 
[68] Sekino, T. (2010) Synthesis and Applications of Titanium Oxide Nanotubes. In: Kijima, T., Ed., Inorganic and Metallic Nan Tubular Materials, Recent Technologies and Applications, X, Springer-Verlag, Berlin Heidelberg, 17-32.

[69] Biswas, K., Bandhoyapadhyay, D. and Ghosh, U.C. (2007) Adsorption Kinetics of Fluoride on Iron(III)-Zirconium(IV) Hybrid Oxide. Adsorption, 13, 83-94. http://dx.doi.org/10.1007/s10450-007-9000-1

[70] Polanyi, M. (1916) Adsorption of Gases by Asolid Non-Volatile Adsorbent. Verhandlungen der Physikalischen Gesellschaftzu Berlin, 18, 55.

[71] Perrich, J.R. (1981) Activated Carbon Adsorption for Waste Water Treatment. CRC Press, Inc., Boca Raton.

[72] Giles, C.H., MacEwan, T.H., Nakhwa, S.N. and Smith, D. (1960) Studies in Adsorption. Part XI. A System of Classification of Solution Adsorption Isotherms, and Its Use in Diagnosis of Adsorption Mechanisms and in Measurement of Specific Surface Areas of Solids. Department of Chemical Technology, The Royal College of Science \& Technology, Glasgow. 